\title{
Correspondence
}

\begin{abstract}
Abuse of psychiatry in Iran
In the past, the Royal College of Psychiatrists has been very active challenging abuse in relation to psychiatry; I distinctly remember, for example, Dr S. Bloch and others successfully exposing abuse of psychiatry in the former Soviet Union in the 1970s.

Why is the College silent about the antediluvian treatment recently endured by Nazanin Zaghari-Ratcliffe in Iran? Simply by exposing such barbaric practice on the international stage and using its authority, the College may succeed where others have failed, namely in ensuring her immediate release.
\end{abstract}

Giuseppe Spoto, Former Visiting Consultant, Priory Hospital. Email: giuseppe.spoto@ntlworld.com

doi:10.1192/bjb.2019.58

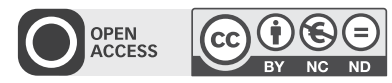

(C) The Author 2019. This is an Open Access article, distributed under the terms of the Creative Commons Attribution-NonCommercial-NoDerivatives licence (http://creativecommons.org/licenses/by-nc-nd/4.0/), which permits noncommercial re-use, distribution, and reproduction in any medium, provided the original work is unaltered and is properly cited. The written permission of Cambridge University Press must be obtained for commercial re-use or in order to create a derivative work.

\section{Response to Dr Spoto}

Dr Giuseppe Spoto asks why the College has not made a statement about the treatment of Nazanin Zaghari-Ratcliffe in Iran and remembers that in the past it has spoken out against abuse of psychiatry in the former Soviet Union in the 1970s.

We remain active in responding to cases where we believe there has been abuse of human rights. We have to be very cautious about making public statements on these issues; we never act until we have taken advice from those working closely with the family and supporters of the individual concerned and from agencies such as Amnesty International. It would be easy to unwittingly make the situation worse for the people involved.

Wendy Burn, President, Royal College of Psychiatrists

doi:10.1192/bjb.2019.60

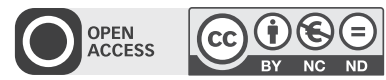

(C) The Author 2019. This is an Open Access article, distributed under the terms of the Creative Commons Attribution-NonCommercial-NoDerivatives licence (http://creativecommons.org/licenses/by-nc-nd/4.0/), which permits noncommercial re-use, distribution, and reproduction in any medium, provided the original work is unaltered and is properly cited. The written permission of Cambridge University Press must be obtained for commercial re-use or in order to create a derivative work.

\section{Provision of weight loss programmes and their influence on weight after 1 year: follow-up survey of usual care in the STEPWISE study}

In 2014, the National Institute of Health and Care Excellence (NICE) recommended that people with psychosis, especially those taking antipsychotic medication, should be offered a combined physical activity and healthy eating intervention. ${ }^{1}$ Moreover, from 2014, Commissioning for Quality and Innovation (CQUIN) supported these recommendations by introducing annual financial incentives to mental health trusts in England to improve their provision of physical healthcare. ${ }^{2}$ However, our previous survey conducted in 2015 of ten UK National Health Service mental health trusts participating in the STEPWISE trial $^{3}$ highlighted that such interventions were largely unavailable, and where programmes were offered these were variable and not always widely accessed. ${ }^{4}$

As a follow-up to our previous survey, ${ }_{1}^{4}$ and in conjunction with the STEPWISE study, ${ }^{3}$ we investigated changes in usual care provision of physical activity and/or healthy eating programmes during the course of the STEPWISE trial. As with the initial survey, mental health professionals completed the survey on behalf of the same ten participating STEPWISE sites.

The number of trusts offering trust-led lifestyle programmes declined from eight to four out of ten during the study. In those trusts not offering programmes, patients were often signposted to externally run services, such as council or voluntary-sector programmes, which was also the case in the first survey.

Seven sites reported changes in services since the previous survey. These included an increased awareness of the need for physical health monitoring; expansion of existing services such as dietitians, healthy living services and gyms; and new provision of services, for instance, one trust had formed a planning group to develop a trust-led programme.

More trusts reported offering support to stop smoking than in the first survey $(60 \%$ v. $30 \%)$, with three trusts either being or becoming smoke free since baseline, and more sites providing access to smoking cessation advisors.

A similar number of surveyed trusts reported recording biomedical measures prior to starting antipsychotic medication, but more trusts reported ongoing monitoring of physical health measures at 1 year than in the first survey, indicating a move towards compliance with the NICE guidelines.

This follow-up survey suggests that trusts are beginning to implement some aspects of NICE physical health recommendations, but the availability of lifestyle programmes offered to patients remains limited. Possibly reflecting the influence of the national CQUIN programme, awareness of the importance of physical health in mental health is increasing, and staff are reportedly more knowledgeable about the services that are available to patients within their trust, including programmes and facilities offered by external services.

Further research would be needed in order to generalise these findings to all UK mental health trusts, as only STEPWISE participating sites were surveyed, which may have resulted in a biased sample. In addition, a longer-term follow-up may have 
revealed more substantial changes by allowing more time to overcome barriers and implement processes.

Lizzie Swaby, Study Manager, Clinical Trials Research Unit (CTRU), University of Sheffield. email: e.a.swaby@sheffield.ac.uk; Richard Holt, Professor in Diabetes and Endocrinology, University of Southampton; Rebecca Gossage-Worrall, Study Manager, CTRU, University of Sheffield; Daniel Hind, Assistant Director, CTRU, University of Sheffield

1 National Collaborating Centre for Mental Health. Psychosis and Schizophrenia in Adults: Treatment and Management. Clinical Guidelines 178. NICE, 2014.

2 NHS England, Commissioning Policy and Primary Care, Commissioning Policy and Resources. Commissioning for Quality and Innovation (CQUIN): 2014/15 guidance. NHS England, 2014 (https://www.england.nhs.uk/wp-content/uploads/2014/12/sc-cquin-guid.pdf).
3 Holt RIG, Gossage-Worrall R, Hind D, Bradburn M, McCrone P, Morris T, et al. Structured lifestyle education for people with schizophrenia, schizoaffective disorder and first-episode psychosis (STEPWISE): randomised controlled trial. BJPsych 2019; 214: 63-73.

4 Swaby L, Hind D, Gossage-Worrall R, Shiers D, Mitchell J, Holt RIG. Adherence to NICE guidance on lifestyle advice for people with schizophrenia: a survey. BJPsych Bull 2017; 41: 137-44.

doi:10.1192/bjb.2019.59

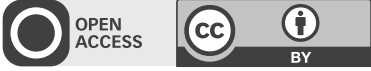

(c) The Authors 2019. This is an Open Access article, distributed under the terms of the Creative Commons Attribution licence (http://creativecommons.org/ licenses/by/4.0/), which permits unrestricted reuse, distribution, and reproduction in any medium, provided the original work is properly cited. 